\title{
Participatory processes in the contemporary city: what is the role of Information and Communication Technologies?
}

SIGRADI2018 TECHNOPOLITICAS xxii congresso da sociedade iberoamericana de gráfica digital 22th conference of the iberoamerican society of digital graphics $07|08| 09 \mid$ novembro|2018 iau usp | são carlos | sp br

\author{
Vítor Domício de Meneses \\ Universidade Federal do Ceará | Brazil | domiciomeneses@yahoo.com.br \\ Daniel Ribeiro Cardoso \\ Universidade Federal do Ceará | Brazil | danielcardoso@ufc.br
}

\begin{abstract}
Urban planning is composed of actions that bring together actors and diverse interests and, therefore, many obstacles. Participation is a fundamental factor for the success of these processes in search of fairer cities as it promotes the exacerbation of conflicts. This research investigates the role of Technologies and Information and Communication (TICs) in participatory processes. For this, virtual participation devices were raised and a connection was made from the established connections between governors and governed. Thus, the objective is to study the potential of ICT use in the construction of more coherent participatory processes.
\end{abstract}

Keywords: Participation; City; Information and Communication Technologies.

\section{INTRODUÇÃO}

O planejamento das cidades é complexo pois lida com um "coletivo social prenhe de conflitos e contradições" (SOUZA, 2006. p.149), manifestado em um território permeado de lutas e debates. Dessa forma, verifica-se que é crescente o desejo de engajamento e participação nos debates públicos, tanto no que se refere a políticas públicas quanto ao planejamento das cidades. A partir da definição de condições que contribuem para a participação popular em políticas públicas (LUCHMANN, 2003), é possível estabelecer parâmetros de análise de diversos processos participativos, possibilitando uma caracterização a partir dos pontos positivos e negativos.

$\mathrm{Na}$ cidade contemporânea, diversas ações do tipo bottom-up, quando uma demanda emerge por inciativa popular até os gestores públicos, se destacam em oposição ao modelo tecnocrático de planejamento e gestão, denominado, portanto, de top-down. Superando barreiras e criando novas possibilidades de atuação (ASCHER, 2010), as Tecnologias de Informação e Comunicação (TICs) permitem que espaços de troca e compartilhamento possibilitem conexões entre governantes e governados. Entre as consequências da inserção destas tecnologias nas cidades contemporâneas está a ampliação do espaço urbano, que se converte em um território híbrido, junção do real e do virtual (FIRMINO E DUARTE, 2008). Para investigar como se dá a utilização das TICs nas dinâmicas colaborativas, este trabalho parte do seguinte questionamento: qual o papel das TICs nos processos participativos contemporâneos?

A partir da caracterização do processo participativo tradicional e do levantamento de dispositivos de participação que funcionam através das TICs, foram estabelecidos parâmetros de análise para estudo e avaliação da eficácia de dispositivos virtuais de participação.

Para compreender de forma global a influência e o alcance das TICs nos processos participativos é preciso ter consciência dos pontos fortes e também das ameaças (GUIMON, 2018) que estas tecnologias oferecem. Questões como violação de segurança em espaços virtuais e veiculação de informações falsas (WARZEL, 2018) são uma realidade e podem modificar completamente o caráter dos processos participativos. $O$ que dificulta a realização de debates e decisões coletivas é a multiplicidade de atores e processos que compõem a cidade. Porém, avaliar a eficiência dessas ações é o primeiro passo para aperfeiçoar o feedback e construir processos mais democráticos e participativos.

Um dos motes do planejamento da cidade é a reflexão sobre as características da cidade desejada. Para que esta reflexão produza uma cidade mais justa e igualitária, ela deve ser realizada de forma conjunta, através de um debate que inclua os diversos grupos sociais e que contemple os conflitos e os impasses existentes. Segundo Christopher Alexander (1998), o processo de crescimento urbano deve ser orgânico, ou seja, capaz de se adaptar às modificações provenientes da natureza e às dinâmicas sociais, e isto só é possível através da participação.

Considerando que a sociedade está organizada a partir de agrupamentos com as mais diversas finalidades, a participação constitui-se como uma característica inata do ser humano, uma necessidade de sentir-se parte, de 
atuar de forma coletiva na construção de um objetivo comum (BORDENAVE, 1983). Este debate ganha maior destaque na conjuntura política brasileira, caracterizada por uma grave crise de representatividade que possui sérias consequências para a cidade. A realização de processos de planejamento urbano sem a participação dos habitantes da cidade enfraquece as dimensões democráticas e prolonga a situação de segregação presente na sociedade.

Na década de 1960, Sherry Arnstein propôs uma classificação referente a participação popular chamada de "escada da participação". O impacto desta classificação perdura até os dias atuais, influenciando o pensamento de planejadores e estudiosos da cidade no debate que envolve o planejamento participativo. A ideia de Arnstein era uma crítica aos processos promovidos pelo Estado, geralmente rotulados de "participativos", mas que, no entanto, nem sempre ocorriam a partir de uma participação popular genuína.

A crítica da autora permanece atual pois, dada a situação de crise pela qual passa a democracia contemporânea, continuam ocorrendo processos ditos participativos sem nenhum comprometimento com as demandas populares. A escada da participação é composta, indo do menor para o maior grau de participação, das seguintes classificações: Manipulação, Terapia, Informação, Consulta, Pacificação, Parceria, Delegação de poder e Controle cidadão.

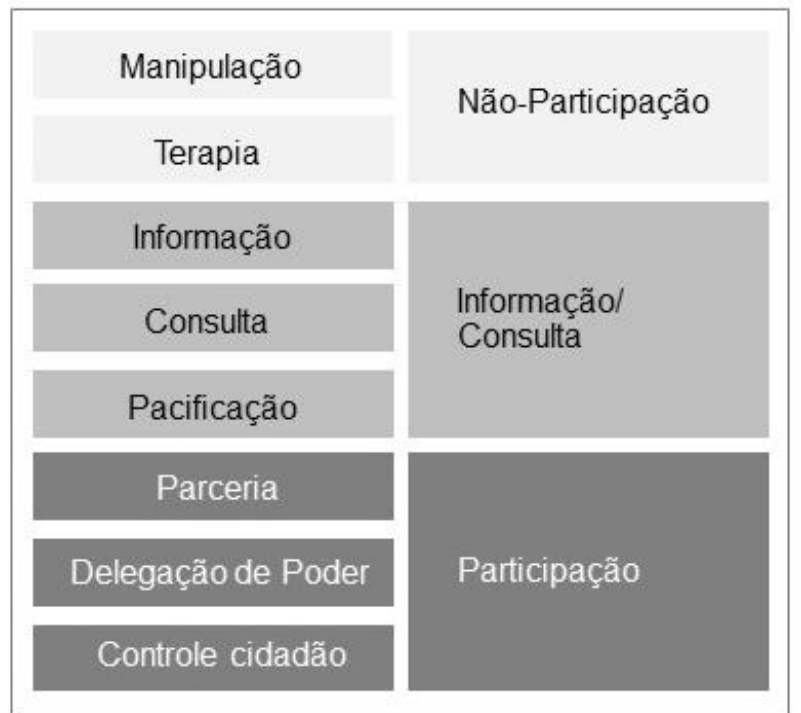

Figura 1: Tipos ou "graus" de participação. Fonte: Elaborado pelos autores com base em Arnstein, 1969.

Segundo a autora, os dois primeiros "degraus" (Manipulação e Terapia) são considerados exemplos de não-participação. Os níveis de informação e consulta abrem um campo maior de possibilidades, porém ainda com diversas restrições já que, apesar de proporcionar o diálogo, não é garantido que o posicionamento da população seja entendido ou acatado no processo decisório. O patamar denominado de Pacificação (entendido também como "apaziguamento") consiste em uma evolução dos dois últimos degraus descritos, com a possibilidade de maior abertura de diálogo. Somente os três últimos degraus representam casos de participação popular genuína, onde é expresso o verdadeiro poder cidadão. No primeiro caso, a população pode realizar uma "Parceria que Ihes permita negociar de igual para igual com aqueles que tradicionalmente detém o poder" (Arnstein, 1969). Nos dois últimos degraus, a população detém a maioria do poder nos processos decisórios ou detém o poder por completo.

Porém, a realização de um processo participativo não é algo simples, sobre isto alguns autores apontam aspectos favoráveis e outros enumeram dificuldades. As condições para que ocorra a participação popular em políticas públicas - definidas por Luchmann, 2003 - são a tradição associativa, a vontade política e o desenho institucional. Pereira (2017) acrescenta mais uma condição: o comprometimento dos técnicos envolvidos com 0 princípio participativo. $\mathrm{O}$ autor também destaca a importância de considerar a influência dos fatores próprios do território em estudo (contexto local). A imagem de um processo participativo é, muitas vezes, a de um processo lento (e, por isso, oneroso e inviável), ineficiente para a escala da cidade e complexo, pela quantidade de atores participantes e a dificuldade de estabelecer acordos.

Segundo Souza (2006), podem ser identificados três tipos de obstáculos à participação popular. O primeiro deles é a cooptação que transforma o processo participativo em "um instrumento de domesticação da sociedade civil por parte das forças políticas à frente do aparelho de Estado." (SOUZA, 2006. p. 410). O segundo obstáculo é definido pelo autor como a problemática da implementação, que reúne todas as dificuldades logísticas enfrentadas para a realização de um processo como esse, tais como incompetências gerenciais, conflitos políticos e ideológicos, pressão de grupos sociais influentes, etc. (SOUZA, 2006. p. 410). E o último aspecto identificado pelo autor é a problemática da desigualdade, referente as dificuldades enfrentadas pelas populações de baixa renda para participar voluntariamente de reuniões e assembléias promovidas em prol de questões coletivas. Essas dificuldades vão desde as privações financeiras até os problemas de disponibilidade de horários, por exemplo, que não comprometam o horário de trabalho. 0 autor cita ainda dificuldades ligadas a autoconfiança dos cidadãos envolvidos, que nem sempre acreditam no potencial de sua participação no processo (SOUZA, 2006. p. 411).

O uso dos novos meios de comunicação, compreendendo-os não somente como tecnologias computacionais de base digital, mas como novas linguagens, vem modificando completamente o modo de vida contemporâneo, tal como descreve Lévy (1999) sobre o "dilúvio de informações", referindo-se a enorme quantidade de dados gerados, compartilhados e consumidos atualmente. Neste sentido, o autor define o conceito de ciberespaço também como "rede", considerando que essa quantidade de informações e dados revoluciona a maneira de comunicar-se e cria um espaço virtual que se torna a extensão do espaço físico.

De fato, as possibilidades de comunicação permitem novas formas de participação, porém, a Internet e suas ferramentas, bem como os aparelhos conectados através da rede, não constituem, sozinhos, uma garantia de participação e, quando esta participação de fato ocorre, não existe garantia da qualidade ou dos impactos. Segundo Gomes (2011), apesar disto, é possível que 
sejam encontradas alternativas de auxílio e incremento para a participação através da Internet, portanto, esta linha de investigação é extremamente relevante (GOMES, 2011).

Entretanto, em um estudo sobre as redes sociais virtuais enquanto espaços de participação, Rocha e Pereira (2011) atestam que a maior parte das plataformas governamentais que utilizam-se das TICs atendem a um modelo de comunicação unidirecional, não permitindo uma interação mais profunda com os cidadãos. A condição de subutilização dessas ferramentas por parte do Estado é um reflexo do que ocorre, grande parte das vezes, com as ferramentas de participação tradicionais ou que não utilizam tecnologias de base digital. Conforme observado no estudo de Arnstein (1969), os diversos tipos de participação demonstram que nem sempre as "rotinas participativas" (SOUZA, 2006) vão além da fase de informação. Entretanto, ainda pode-se considerar que a divulgação de informações relativas a gestão e suas ações é um passo importante para a conquista de um novo patamar de controle social.

\section{METODOLOGIA}

A partir de um levantamento bibliográfico foi desenvolvido um debate teórico sobre processos participativos e a utilização de Tecnologias de Informação e Comunicação (TICs) na cidade contemporânea. Visando investigar como as TICs podem contribuir na criação de espaços democráticos de debate, foi realizado um levantamento de diversos dispositivos de participação que funcionam através de sites, aplicativos, etc. Baseando-se em Luchmann (2003), Pereira (2017) e Arnstein (1969), este trabalho propõe uma análise da atuação destes dispositivos nos processos participativos. Com isto, pretende-se refletir sobre o papel das TICs nos processos participativos e, além disso, questionar sobre as formas de utilização destes dispositivos enquanto meios de comunicação na cidade contemporânea.

\section{RESULTADOS}

A partir dos objetivos, de forma de interação com o usuário e da logística de ação, foi proposta uma classificação dos dispositivos em três tipologias: Dispositivos de Informação, Dispositivos de Mobilização e Ativismo e Dispositivos Didáticos e de Pesquisa.

A primeira tipologia, os chamados Dispositivos de Informação, é, talvez, a mais tradicional e tem como exemplo os portais de informação governamentais. Este tipo de dispositivo tem o objetivo de fornecer informações. No caso dos portais governamentais, são sites criados para divulgar informações da gestão municipal, estadual ou federal e funcionam, na maior parte das vezes, apenas como ambientes de marketing político, exibindo dados previamente selecionados para construir uma imagem positiva das ações realizadas pelo poder público. No caso de serem mantidos por iniciativas da sociedade sem vínculos governamentais, assumem um papel de apoio ao controle social quando fornecem informações estratégicas para os cidadãos. O objetivo desse tipo de dispositivo está relacionado ao compartilhamento de informações para que o cidadão acompanhe os acontecimentos e possa agir. No entanto, nem sempre há espaço para interação com o usuário. Mesmo assim, configura-se como uma iniciativa interessante pois o acesso à informação é o primeiro passo do processo de participação no planejamento do espaço.

Um dos exemplos desta tipologia, o Mapeamento colaborativo do IPLANFOR (Instituto de Planejamento de Fortaleza, Prefeitura de Fortaleza), é uma plataforma de mapas abertos para inserção de dados pelos usuários. Porém, nem todos os dados são utilizados para fins de planejamento e não existe um controle exato para selecionar os dados relevantes e otimizar o serviço. Neste caso, não há nenhuma abertura para o diálogo entre o usuário e a prefeitura.

Outro exemplo é o Observatório Cidadão de Piracicaba, uma plataforma criada por um conjunto de entidades públicas e privadas com 0 intuito de compartilhar informações de interesse do cidadão na esfera municipal. Se intitulando como uma ferramenta de controle social, o observatório reúne informações divididas em Meio Ambiente, Metas, Participação Social e Transparência Pública. Os dados são apresentados sob a forma de indicadores que foram construídos a partir de fontes diversas, permitindo ao cidadão realizar análises sobre a construção e implementação de políticas públicas do município. Assim como foi descrito a tipologia Informação, - Observatório de Piracicaba também não permite a interação com os usuários do Portal, apenas fornecendo as informações e as fontes para que o cidadão assuma uma conduta ativa em outro espaço, ou seja, configurando-se como um ambiente de coleta e compartilhamento de informações.

A segunda tipologia, Dispositivos de Mobilização e Ativismo, também pode ser chamada de "rede" pois fornece aos seus usuários a possibilidade de conectar-se a outros cidadãos (mobilização) e aos tomadores de decisão (pressão e feedback). A transformação da conduta de cidadão passivo, apenas consumidor de informações, para a conduta de cidadão ativo, que integra-se em um movimento maior de mobilização e ativismo, é possibilitada a partir da mudança de relação entre portal e usuário. Os objetivos deste tipo de dispositivo são relativos à ações concretas dos cidadãos. Desde o mecanismo de petições online (que apenas modificou o meio de coletar assinaturas) até a possibilidade de aprovar projetos de lei de inciativa popular, todas essas ferramentas pressupõem a participação do cidadão no debate de questões coletivas sobre a cidade e o país.

Um dos exemplos desta tipologia é o Nossas, uma organização que se define como apartidária e sem fins lucrativos para dar voz às demandas propostas por cidadãos através de uma rede de mobilização e ativismo em diversas cidades do Brasil. Atuando como incubadora de organizações a nível municipal (Meu Rio, Minha Sampa, Meu Recife) para mobilizar e agir em prol das causas locais, a rede é composta de voluntários que unem as pessoas para reivindicar ações ao poder público. O nossas, através das suas redes municipais criou e geriu algumas ferramentas, tais como a Panela de Pressão (para pressionar tomadores de decisão em prol de causas sociais), a Legislando (para apoiar e promover projetos de lei de inciativa popular) e a De Guarda (para possibilitar "vigílias" virtuais em edificações ou locais ameaçados de demolição ou ocupação indevida). 
Neste sentido, outro caso de Dispositivo de Mobilização e Ativismo é o Change.org, uma plataforma virtual de construção de abaixo-assinados sobre diversos temas de interesse público que apoia iniciativas em várias partes do mundo. O sistema funciona da forma tradicional de um abaixo-assinado, porém, com o auxílio da internet e da inteligência artificial, a plataforma faz com que o abaixoassinado seja visto por pessoas que se interessam pelo tema e que, ao final, o resultado chegue aos tomadores de decisão, pressionando-os e influenciando sua conduta.

A terceira e última tipologia de dispositivo, os Dispositivos Didáticos e de Pesquisa, assemelha-se a tipologia Dispositivos de Informação, porém, inserindo mecanismos de interatividade e permitindo analises, comparações e configurações na exibição dos dados. Muitas vezes criados através da associação de empresas e instituições particulares, esses dispositivos, embora também objetivem o compartilhamento de informações para empoderar os cidadãos, também possuem uma preocupação didática e de pesquisa. Além de fornecer dados para o usuário, esses portais também oferecem mecanismos interativos de organização e análise desses dados, adicionando mais complexidade na construção de cenários e no agrupamento de informações.

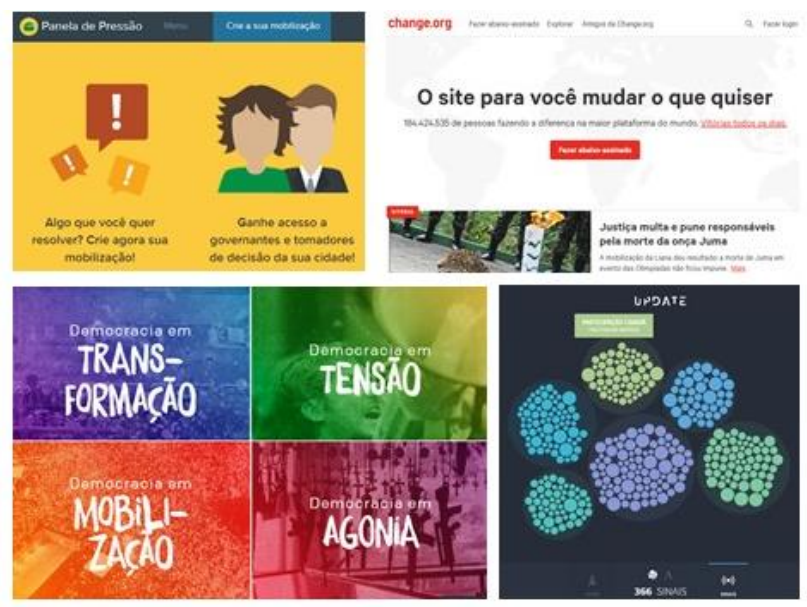

Figura 2: Dispositivos de participação. Fonte: Meneses, 2017.

Um exemplo desta tipologia é o Alerta Democrático, uma plataforma de construção de cenários relativos à democracia na América Latina, realizando previsões permitindo a realização de buscas e pesquisas relacionadas a diversos temas. Formada por líderes de diversos países do continente latino-americano, a plataforma trabalha com a metodologia de Planejamento de Cenários Transformadores.

Outra iniciativa classificada como Dispositivo Didático e de Pesquisa é o Update Politics - Laboratório de Inovação Política na América Latina, que reuniu diversas ações de controle cidadão e participação democrática em uma rede de redes, possibilitando a integração e a troca de ideias entre os grupos. A plataforma realizou uma pesquisa de iniciativas democráticas na América Latina geralmente com uso da Internet - utilizando como background o contexto sóciopolítico do continente. Os dados sobre estes grupos de diferentes países da América Latina foram classificados e divididos em grupos de acordo com seus objetivos e possibilidades de atuação oferecidas. O resultado é um panorama de ações emergentes na no continente fortalecidas pela rede.

\section{DISCUSSÃO}

Segundo Vieira (2008), parâmetros evolutivos são aqueles que expressam a temporalidade de qualquer sistema. Encarando 0 processo de planejamento participativo como um sistema composto de diversas partes que se relacionam, dois destes parâmetros são relevantes para esta análise: conectividade e estrutura. Segundo o autor, a conectividade é a capacidade que os elementos de um sistema têm de estabelecer conexões ou relações entre si. Já estrutura ocorre quando as relações são estabelecidas, é a conexão de fato (VIEIRA, 2008). Ou seja, a conectividade representa a possibilidade, a estrutura representa o fato ocorrido.

A adoção deste referencial possibilita a compreensão da abrangência da conectividade proporcionada pelo uso das TICs, especificamente em processos participativos. As novas conexões, os novos espaços de produção e compartilhamento de informações estabelecidos pelo uso das TICs representam possibilidades de conexão entre atores sociais, porém não representam estas conexões de fato.

Os dispositivos virtuais de participação apresentados neste trabalho operam sobre a conectividade ampliando as possibilidades de efetivação de novas conexões, em muitos casos, com agilidade e eficiência. Em certos casos também possibilitam tipos de relações nunca antes experimentadas, atributo próprio da tecnologia que representam. Por outro lado, as ferramentas participativas tradicionais guardam um atributo fundamental que não pode e nem deve ser substituído: a presença física, a atuação materializada no espaço urbano.

Esclarecido o conceito de conectividade e compreendendo, a partir disto, a condição de potência que as TICs têm para o planejamento urbano, faz-se necessário refletir sobre a efetivação destas conexões. É preciso considerar que o estabelecimento de um canal de relação entre um cidadão e um gestor não significa necessariamente a construção de uma atividade democrática e inclusiva de planejamento da cidade. Nos casos em que a conexão é de fato estabelecida, a análise deve ocorrer sobre a qualidade e a efetividade do contato proporcionado.

Ainda utilizando o embasamento teórico sobre sistemas, segundo Denbigh (1975 apud VIEIRA, 2008) as conexões podem ser ativas, quando permitem o intercâmbio de informações; indiferentes, quando são indiferentes a este intercâmbio; e podem ser opostas ou contrárias, quando bloqueiam o transporte de informações. Esta classificação corrobora com os tipos de dispositivos definidos nesta pesquisa.

Os dispositivos do tipo mobilização/ativismo estabelecem conexões do tipo ativas, tais como as redes sociais virtuais que funcionam como espaços democráticos de comunicação multidirecional, permitindo que os elementos conectados exerçam influencia uns sobre os outros, ou mesmo que, num sistema complexo, eles consigam modificar o espaço de conexão, definindo outras configurações de estruturas. Os dispositivos do tipo didáticos podem estabelecer conexões do tipo indiferente já que muito deles são indiferentes - e muitas vezes até estanques - na transmissão das informações 
que exibem, ou seja, o fato de o usuário acessar e utilizar as informações desses dispositivos não possui qualquer influência no espaço criado ou no tipo de conexão. Nos dispositivos do tipo informação, no caso específico dos portais governamentais, o fluxo de informações é, na maioria das vezes, unidirecional. Dessa forma, pode-se dizer que as conexões que estes dispositivos estabelecem são do tipo opostas ou contrárias, já que bloqueiam o transporte de informações e/ou selecionam os dados a serem exibidos, fato que também atinge o debate sobre a transparência dos dados na administração pública. Abaixo propõe-se uma tabela-síntese da correspondência descrita entre tipos de conexão e tipos de dispositivo.

Tabela 1: Correspondência entre tipos de dispositivo e tipos de conexão. Fonte:elaborado pelos autores.

\begin{tabular}{|l|l|l|}
\hline TIPO DE & TIPO DE & EXEMPLO DE \\
DISPOSITIVO & CONEXÃO & DISPOSITIVO \\
\hline Informação & $\begin{array}{l}\text { Opostas ou } \\
\text { contrárias }\end{array}$ & $\begin{array}{l}\text { Portais } \\
\text { governamentais }\end{array}$ \\
\hline $\begin{array}{l}\text { Mobilização/ } \\
\text { Ativismo }\end{array}$ & Ativa & $\begin{array}{l}\text { Redes de } \\
\text { mobilização, } \\
\text { petições online }\end{array}$ \\
\hline Didáticos & Indiferente & $\begin{array}{l}\text { Portais de } \\
\text { pesquisa }\end{array}$ \\
\hline
\end{tabular}

Com isto, pode-se concluir que a exclusão da população nos processos de planejamento da cidade faz parte de um contexto de manutenção das relações de poder existentes. Portanto, o acesso às redes conectadas não garante 0 acesso aos processos decisórios (ainda que somente a título de informação). O processo de tomada de decisão está fechado seletivamente por barreiras que vão além da rede virtual. Aspectos socioeconômicos, culturais, locais e, sobretudo, as relações de poder existentes são os fatores que atuam para a manutenção das condições de funcionamento do planejamento tecnocrático.

A proposta desenhada neste trabalho é a da reflexão acerca do planejamento participativo. Tratando-se de tarefa complexa, tal como é o planejamento de cidades, é preciso reconhecer os dispositivos de participação tradicionais e virtuais - seus potenciais e seus problemas, e analisá-los à luz das necessidades existentes. Se é verdade que os métodos tradicionais de planejamento urbano participativo trazem consigo um conjunto de dificuldades na execução dos processos - muitas delas ligadas a comunicação, a representação e a democratização - como ignorar o potencial trazido pelas TICs nos estudos urbanos e nos processos participativos?

Pierre Lévy (1999) já defendia que o debate acerca da informática não ocorresse sobre o patamar do determinismo tecnológico pois acreditava que 0 preconceito acerca das inovações faz com que estejamos ainda mais reféns delas. No caso do planejamento urbano - que na maior parte das vezes tem como protagonista o Estado - é impossível ignorar os avanços relativos aos mapas colaborativos, aos aplicativos de registro de ocorrências urbanas, aos sistemas de transporte integrados. Sob a perspectiva do cidadão, também é relevante considerar às inúmeras redes de monitoramento popular que emergem de grupos da sociedade estimulados pela atual crise de representatividade política.

Porém, apenas conhecer os avanços da utilização das TICs não é suficiente. É preciso e é essencial que o planejamento de uma cidade incorpore essas iniciativas (populares e governamentais), juntando-as ao grupo dos dispositivos de participação tradicionais e montando um sistema de suporte ao planejamento participativo.

Com estes argumentos, porém, a pesquisa não tem a intenção de ignorar a falibilidade dos dispositivos estudados, bem como o largo conjunto de fatores que influenciam opiniões e ações nos espaços virtuais. Sabese que a democracia exercida nos espaços virtuais deve considerar, sob pena de ter sua legitimidade questionada, as limitações que o próprio espaço virtual Ihe impõe, tais como a falsa identidade, a manipulação e falsificação de dados e mídias (GUIMÓN, 2018; WARZEL, 2018). As redes sociais, por exemplo, permitem ao usuário participar de grandes movimentos somente com uma interação vitual, sem maiores comprometimentos.

Para além dessa análise preliminar, deve-se considerar ainda que o impacto dos dados da internet representa um grande potencial de mobilização popular, mas também representa diversas possibilidades de manipulação e cooptação exercidas no espaço das redes virtuais. Neste sentido, almejando construir um modelo de planejamento e gestão através de processos genuinamente participativos, é preciso considerar avanços e retrocessos no uso das TICs em diversas instâncias. Considerando a complexidade da cidade e das diferentes ferramentas necessárias (tradicionais e virtuais), é preciso refletir sobre um sistema de controle social e participação cidadã que proporcione uma atuação baseada em um contínuo processo de feedback popular.

\section{REFERÊNCIAS}

ALEXANDER, C. (1998) Urbanismo y Participación. Barcelona: Gustavo Gili.

BORDENAVE, J. E. D. (1983) O que é participação? São Paulo: Editora Braziliense.

ASCHER, F. (2010) Os novos princípios do urbanismo. São Paulo: Romano Guerra.

ARNSTEIN, S. R. (1969) A ladder of citizen participation. Journal of the American Institute of Planners, v. 35, jul, p. 216-24: 1969.

FIRMINO, R.; DUARTE, F. (2008) Cidade infiltrada, espaço ampliado. Arquitextos, São Paulo, 096.01, Vitruvius, maio $2008 . \quad$ Retrieved from <http://www.vitruvius.com.br/revistas/read/arquitextos/08.096 /3408>.

GOMES, W. (2011) Participação política online: questões e hipóteses de trabalho. In: ROUSILEY, C. M. M.; GOMES, W.; Marques, F. P. J. A. (Org.). Internet e participação política no Brasil. Porto Alegre: Sulina.

GUIMÓN, P. (2018). O 'Brexit' não teria acontecido sem a Cambridge Analytica. El País 26 mar. 2018. Retrieved from <https://brasil.elpais.com/brasil/2018/03/26/internacional/152 2058765_703094.html>.

LÉVY, P. Cibercultura (1999). Tradução de Carlos Irineu da Costa. São Paulo: Editora 34. 
LUCHMANN, L. H. H. (2003) Redesenhando as relações entre sociedade e Estado: o tripé da democracia deliberativa. Katálisis v. 6 n. 2 p. 165-168. Florianópolis, jul-dez, 2003.

MENESES, V. D. (2017) Participação na era da informação : uma Análise do uso das TICs nos processos participativos. Dissertação (mestrado) - Universidade Federal do Ceará, Centro de Tecnologia, Programa de Pós- Graduação em Arquitetura e Urbanismo e Design. 118 f. Fortaleza.

PEREIRA, E. M. (2017) Como anda a participação? As condições para elaboração de Planos Diretores Participativos. Revista Brasileira de Estudos Urbanos e Regionais, v. 19, n. 2 p. 235-250. Recife, maio-ago, 2017.
ROCHA, M. F.; PEREIRA, G. C. (2011) Mídias Sociais e espaços de participação. Simpósio em Tecnologias Digitais e Sociabilidade. Salvador.

SOUZA, M. L. de (2006). A prisão e a ágora: reflexões em torno da democratização do planejamento e da gestão das cidades. Rio de Janeiro: Berttrand Brasil.

VIEIRA, J. A. (2008) Ontologia: Formas de conhecimento. Arte e ciência uma visão a partir da complexidade. Fortaleza: Expressão Gráfica e Editora.

WARZEL, C. (2018) Ele previu a crise de notícias falsas em 2016. Agora está preocupado com um apocalipse de informações. Buzz Feed News 23 mar. Retrieved from <https://www.buzzfeed.com/charliewarzel/apocalipseinformacoesinternet?utm_term=.rgayO5j15v\#.iv1yYmw0mg>. 